\title{
The photodynamic and non-photodynamic actions of porphyrins
}

S.G. Afonso $0^{1,2}$

R. Enríquez de Salamanca and A.M. del C. Batlle ${ }^{1}$

\author{
Correspondence \\ A.M. del C. Batlle \\ Viamonte, 1881, 10 "A" \\ 1056 Buenos Aires \\ Argentina \\ Fax: +54-11-4811-7447 \\ E-mail: cipyp@alad.fcen.uba.ar \\ Research supported by CONICET \\ from Argentina, and FISss (No. 93/ \\ 112) and Ministerio de Educación y \\ Ciencia from Spain. S.G. Afonso \\ was the recipient of post-doctoral \\ fellowships from the Instituto de \\ Cooperación Iberoamericana $(\mathrm{ICl}$, \\ Spain), the Directorate General for \\ Science, Research and Development \\ at the Commission of the European \\ Communities (Belgium), and the \\ CONICET (Argentina).
}

Received March 5, 1998 Accepted December 9, 1998

\author{
${ }^{1}$ Centro de Investigaciones sobre Porfirinas y Porfirias (CIPYP), \\ Consejo Nacional de Investigaciones Científicas y Técnicas (CO NICET), \\ Facultad de Ciencias Exactas y N aturales, U niversidad de Buenos Aires, \\ Buenos Aires, Argentina \\ ${ }^{2}$ Unidad de Porfirias, Hospital Universitario 12 de Octubre, Madrid, Spain
}

\section{Abstract}

Porphyrias are a family of inherited diseases, each associated with a partial defect in one of the enzymes of the heme biosynthetic pathway. In six of the eight porphyrias described, the main clinical manifestation is skin photosensitivity brought about by the action of light on porphyrins, which are deposited in the upper epidermal layer of the skin. Porphyrins absorb light energy intensively in the UV region, and to a lesser extent in the long visible bands, resulting in transitions to excited electronic states. The excited porphyrin may react directly with biological structures (type I reactions) or with molecular oxygen, generating excited singlet oxygen (type II reactions). Besides this well-known photodynamic action of porphyrins, a novel light-independent effect of porphyrins has been described. Irradiation of enzymes in the presence of porphyrins mainly induces type I reactions, although type II reactions could also occur, further increasing the direct non-photodynamic effect of porphyrins on proteins and macromolecules. Conformational changes of protein structure are induced by porphyrins in the dark or under UV light, resulting in reduced enzyme activity and increased proteolytic susceptibility. The effect of porphyrins depends not only on their physico-chemical properties but also on the specific site on the protein on which they act. Porphyrin action alters the functionality of the enzymes of the heme biosynthetic pathway exacerbating the metabolic deficiencies in porphyrias. Light energy absorption by porphyrins results in the generation of oxygen reactive species, overcoming the protective cellular mechanisms and leading to molecular, cell and tissue damage, thus amplifying the porphyric picture.

\section{Porphyrins and porphyrias}

Porphyrias are a family of inherited diseases, each associated with a partial defect in one of the enzymes of the heme biosynthetic pathway (1) (Figure 1). As a consequence, each porphyrinopathy shows specific meta-

\section{Key words}

- Photodynamic

- Porphyrias

- Porphyrins

- Protein alterations bolic abnormalities reflected by diagnostic laboratory findings in blood, urine and feces. Based on the main clinical manifestation, porphyrias are currently classified into "acute" and "non-acute" (2) (Table 1).

In six of the eight described porphyrias, the main clinical feature is skin photosensi- 


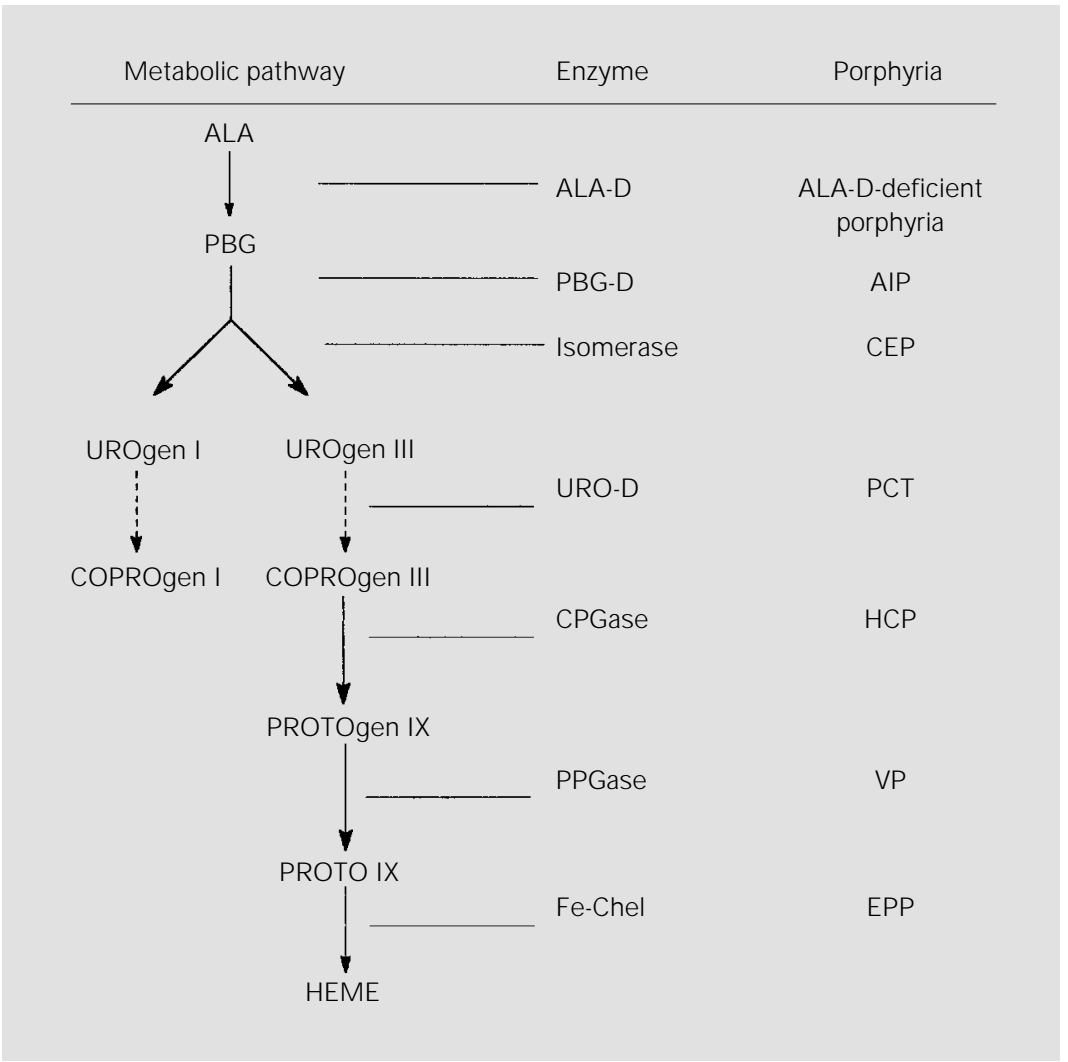

Figure 1 - Heme biosynthetic pathway. AIP: Acute intermittent porphyria; ALA: $\delta$-aminolevulinic acid; ALA-D: $\delta$-aminolevulinic acid dehydratase; CEP: congenital erythropoietic porphyria; COPROgen: coproporphyrinogen; CPGase: coproporphyrinogen oxidase; EPP: erythropoietic protoporphyria; Fe-Chel: ferrochelatase; HCP: hereditary coproporphyria; PBG: porphobilinogen; PBG-D: porphobilinogen deaminase; PCT: porphyria cutanea tarda; PPGase: protoporphyrinogen oxidase; PROTOgen: protoporphyrinogen; URO-D: uroporphyrinogen decarboxylase; UROgen: uroporphyrinogen; VP: variegate porphyria.

Table 1 - Classification of porphyrias.

Hepatic

1. Acute intermittent porphyria (AIP)

2. ALA-D-deficient porphyria

3. Variegate porphyria (VP)

4. Hereditary coproporphyria (HCP)

5. Porphyria cutanea tarda (PCT)

Erythropoietic

6. Erythropoietic protoporphyria (EPP)

7. Congenital erythropoietic porphyria (CEP)

Hepato-erythropoietic

8. Hepato-erythropoietic porphyria (HEP) tivity brought about by the action of light on porphyrins, which are deposited in the upper epidermal layer of the skin.

Porphyrins absorb radiant energy intensively in the UV region, at their Soret band (400-410 nm) and to a lesser extent in the long visible bands (580-650 nm), resulting in transitions to excited electronic states (Figure 2). In the cutaneous porphyrias, skin lesions are due to these properties of porphyrins. The excited porphyrin may react directly with biological structures (type I reactions) or with molecular oxygen, generating excited singlet oxygen (type II reactions). Singlet oxygen in turn damages tissues through several mechanisms, including oxidation of membrane lipids and amino acids in proteins, cross-linking of proteins and oxidative damage to nucleic acids with the consequent disturbance of the normal functioning of cellular activities or organelles. In addition to singlet oxygen, the other reactive oxygen species (ROS), $\mathrm{O}_{2}{ }^{\bullet-}, \mathrm{H}_{2} \mathrm{O}_{2}$, and ${ }^{\bullet} \mathrm{OH}$ are also formed, which are also important in the progress of porphyrin photosensitization (3) (Figure 3).

One striking feature of cutaneous porphyrias is the heterogeneity of their appearance, which can be considered to be of two types: acute and chronic.

The pattern of acute photosensitivity, mostly seen in the erythropoietic porphyrias, is characterized by subjective complaints of painful burning and itching, often associated with pruritus and edema. Repetition of these episodes of acute photosensitization may end in scarring, with the aspect of wax-like linear bands, mainly in the nose, ears and dorsum of the hand in the erythropoietic protoporphyria (EPP) (4).

Chronic photosensitivity is characterized by the gradual onset of notoriously increased skin fragility of the exposed areas, manifesting as vesicles and bullae, very often exhibiting hemorrhagic bases which slowly crust and heal, yielding milia, typical of porphyria cutanea tarda (PCT) (4). 
The different responses to light are related to the physicochemical properties of the various types of porphyrin molecules accumulated in each porphyria. It has been demonstrated that protoporphyrin (PROTO) accumulates predominantly in mitochondria and is inserted into biological membranes, while uroporphyrin (URO) accumulates mainly in lysosomes and is not associated with membranes (5). Consequently, different porphyrins should also have different effects on specific cell types.

\section{Photodynamic and non-photodynamic action}

The photodamage mechanisms induced by porphyrins have been extensively investigated. The effect of porphyrins as exogenous and endogenous sensitizers has been studied in a wide variety of biological environments and targets for the phototoxic damage, i.e., lipid and protein solutions $(6,7)$, isolated erythrocyte membranes (8-10), whole erythrocytes (11-13), subcellular organelles (5, 14,15), mammalian tissue and cell cultures $(16-18)$ as well as animal $(19,20)$ and human (21) models.

The wavelength of light preferentially absorbed by porphyrins can penetrate through the epidermis. UV and visible radiation reaches the level of cutaneous blood vessels (22). It would appear, however, that the wavelength of greatest clinical significance in the production of porphyric skin lesions is in the violet Soret band. UV rays are the most efficient producers of singlet-excited porphyrins. The bulk of the abnormalities observed histologically occur in the lower epidermal and upper dermal skin layers reached by these radiations.

The relative cytotoxic efficiency of several porphyrins covering the whole range from high water solubility to virtual water insolubility was evaluated in cell culture (23-25). Cells were incubated with media containing different porphyrins and then ex- posed to light irradiation. Each culture was subsequently assessed for three parameters of porphyrin-mediated photodamage: a) ability of the cells to transport radiolabeled cycloleucine across the cell membrane, b) decrease in cell-surface hydrophobicity, and c) the degree of cross-linking of the proteins in the cell membrane. The conclusion drawn from these studies was that the hydrophobic porphyrins were in closer approximation to the target molecules of these membranes and were, therefore, in a better position to perform photodynamic reactions more efficiently, thus producing membrane damage and eventually cell death (23). It was also demonstrated that PROTO, a highly hydrophobic porphyrin, provoked more severe photodynamic damage in rat liver mitochondria than did coproporphyrin (COPRO), a molecule with intermediate water-solubility (24). In turn, COPRO was more efficient in sensitizing mitochondrial damage than was URO, the most hydrophilic porphyrin (24). Further studies showed that the key determinants for the photodynamic effectiveness lie in the solubility properties of the porphyrin sensitizer relative to the hydrophilic or hydrophobic nature of the target biomolecules, with PROTO being most phototoxic to lipophilic structures, such as erythrocyte membranes, mitochondrial preparations and membrane-

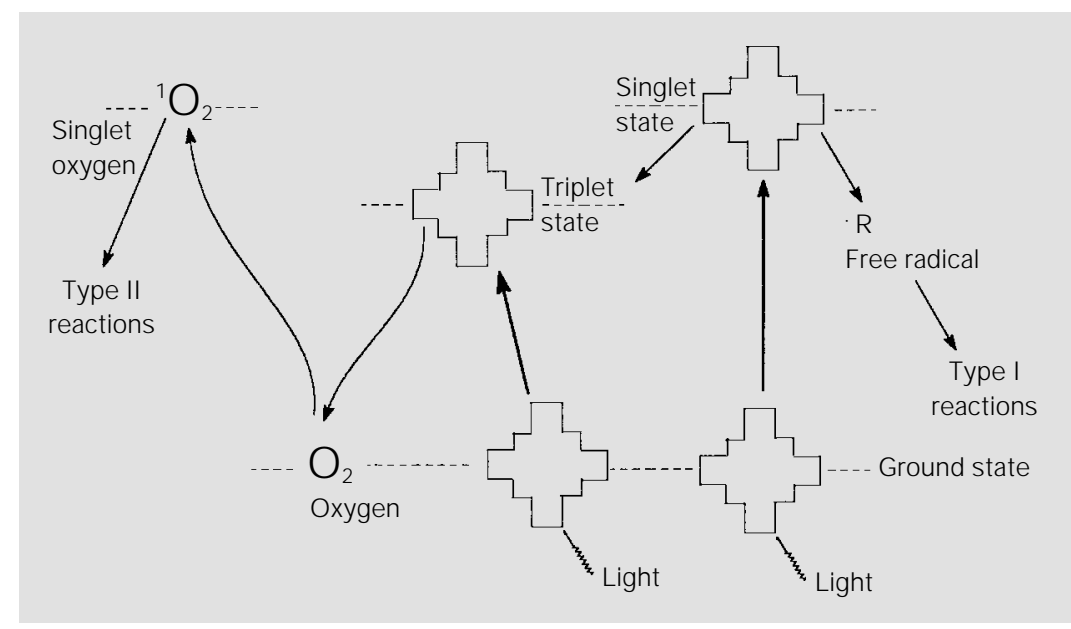

Figure 2 - Energetic transitions in porphyrins. 
bound enzymes, and URO more efficient in the photodamage to soluble structures $(5$, 14,16).

These in vitro results support the theory put forward for the pathogenesis of the clinical phototoxic symptoms of EPP that proposes that the rapid destruction of dermal capillary endothelial cells, whose lipoprotein membranes are constantly bathed with PROTO transported by albumin and hemopexin in plasma (26), is the initial toxic event. Damaged endothelial cells would then become incompetent, leaking their intravascular content into the dermis. Release of histamine, lysosomal acid hydrolases, or other organelle-bound inflammatory mediators could also participate in the evolving reaction after PROTO-sensitized lysis of the organelle membranes has taken place, thereby eliciting the painful skin sensations immediately noticed by porphyric patients after exposure to sunlight (27).

According to this theory, hydrophilic porphyrins would be less attracted to lipophilic membrane sites, and would therefore be less efficient sensitizers for membrane damage. The more water-soluble porphyrins may preferentially photosensitize biomolecular targets in the epidermis and at the basement membrane level, but their mechanism is still unclear, and at present there are only speculations. One theory proposes that these sites are relatively hydrophilic, and therefore they show greater affinity for hydrophilic por- phyrins transported to their neighborhood in the extravascular fluid space (27). An alternative theory holds that these hydrophilic porphyrins are actually synthesized de novo in or near these sites of accumulation, reflecting the universality of the genetic defect present, but operative at different levels in all somatic cells $(27,28)$.

Even less clear are the determinants of the clinical phototoxicity patterns in porphyrias exhibiting accumulation of virtually the whole spectrum of hydrophobic and hydrophilic porphyrin molecules. Patients with variegate porphyria (VP) accumulate large amounts of 2- and 3-carboxylic porphyrins and unusual complexes of porphyrins with peptides, proteins, or other carriers, which have been found in feces (29) and plasma (29-31). It can also be speculated that the highly hydrophobic 2- and 3-carboxyl porphyrins, and the relatively hydrophobic 4carboxyl porphyrins synthesized in hepatocytes, in VP, are efficiently cleared into the biliary and fecal compartments, where they can be detected in high quantity, but poorly disseminated by plasma into skin $(27,31)$.

Besides the photodynamic action, a novel light-independent effect of porphyrins on biomolecules has been described not long ago. In 1982, it was reported that URO stimulates collagen biosynthesis in human skin fibroblasts (32), and that PROTO activates guanylate cyclase in the dark (33). Decreased cytochrome c oxidase activity and increased
Figure 3 - Reactive oxygen species.

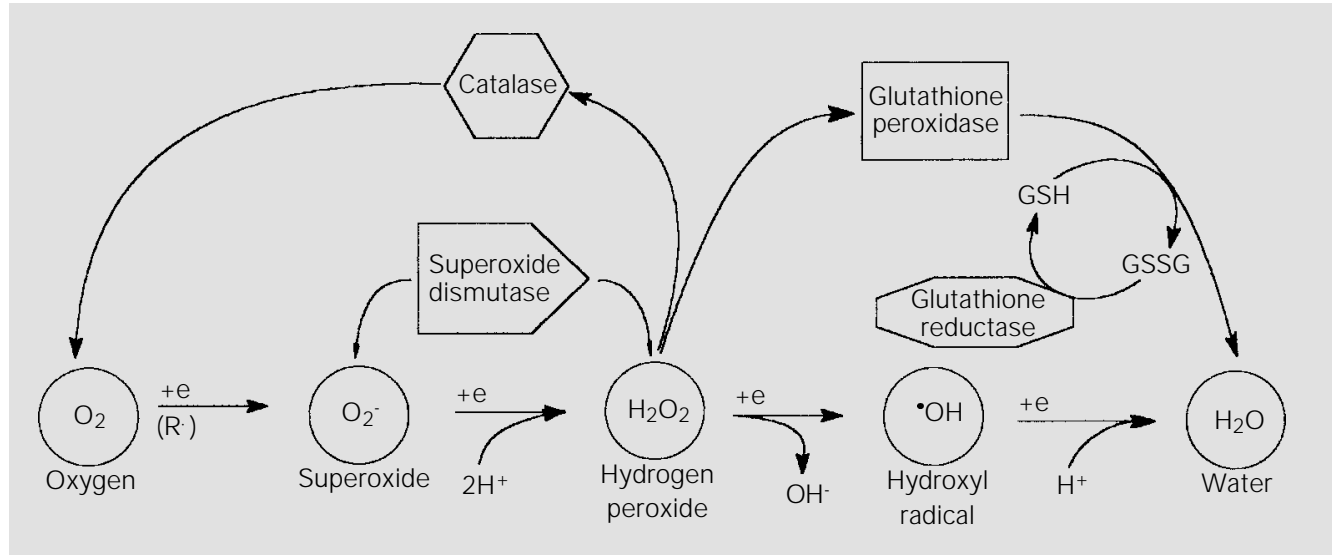


lactate production and glucose utilization were induced by porphyrin derivatives in cell cultures (34). The potentiating action of hematoporphyrin on the horseradish peroxidase-catalyzed oxidation of NADPH in the dark has been demonstrated $(35,36)$, and the interaction of PROTO with redox systems such as the Haber-Weiss and Fenton reactions, possibly yielding an electronically excited porphyrin, has also been observed in the dark (37). However, there is still much to learn about the reactivity of tetrapyrroles in the dark.

\section{Light-dependent and light-independ- ent enzyme inactivation}

Circulating porphyrins absorb the light energy that reaches cutaneous vessels, triggering a series of reactions which affect not only the surrounding cellular structures, but that can also alter the functionality of the erythrocyte enzymes. These excited porphyrins could extend their noxious action to the various organs they reach by the blood stream. In addition to these light effects, alterations induced by porphyrins in the dark should be considered. Therefore, it is expected that the photodynamic and non-photodynamic action of porphyrins would add to the established heme enzyme deficiencies in porphyrias, worsening the already disturbed picture.

On this basis, a series of in vitro studies to investigate the alterations induced by porphyrins on several heme enzymes and trying to elucidate their mechanism of action have been carried out.

It was observed that URO I per se inactivates erythrocyte $\delta$-aminolevulinic acid dehydratase (ALA-D), porphobilinogenase (PBGase), porphobilinogen deaminase (PBG-D) and uroporphyrinogen decarboxylase (URO-D) in the dark; this inactivation was greater when enzymes were exposed to UV light in the presence of the porphyrin. Both the photodynamic and non-photody- namic actions of URO I were dependent on concentration, temperature and time of exposure of the proteins to the porphyrin (3840).

URO I-induced inactivation was also observed with other enzymes. Thus, $\delta$-aminolevulinic acid synthetase lost $70 \%$ and rhodanese lost $95 \%$ of their activity upon 30 min of exposure to $10 \mathrm{mM} \mathrm{URO} \mathrm{I} \mathrm{and} \mathrm{light,}$ while succinyl CoA synthetase and lactic acid dehydrogenase activities decreased 70 and $50 \%$, respectively. Enzyme activities were also reduced by URO I in darkness, although dark-inactivation was lower than light-inactivation (41).

Besides URO I, the action of other porphyrins on the activity of human erythrocyte ALA-D, PBGase, PBG-D and URO-D was investigated. Both photo- and non-photoinactivation were found to occur in all four enzymes, with the light-dependent effect again being greater than the dark effect (42).

Aerobic and anaerobic studies have demonstrated that oxygen is required for the photodynamic action of URO I, since under a nitrogen atmosphere similar inactivation was found whatever the light condition, and this inactivation was of the same degree as that found when the enzymes were exposed to porphyrins in the dark and in aerobiosis (Table 2) (43).

From these results it emerged that porphyrins exert a double effect on the enzymes. The dark inactivation would be the

Table 2 - Percentage of enzyme inactivation induced by URO I. Effect of the presence of oxygen.

Enzymes were exposed to $10 \mu \mathrm{M}$ URO I (ALA-D, PBGase or PBG-D) or $100 \mu \mathrm{M}$ URO I (URO-D) at $37^{\circ} \mathrm{C}$, in an oxygen $\left(\mathrm{O}_{2}\right)$ or nitrogen $\left(-\mathrm{O}_{2}\right)$ atmosphere. Porphyrin was removed after $2 \mathrm{~h}$, and enzyme activities were measured.

\begin{tabular}{lllccc}
\hline & & ALA-D & PBGase & PBG-D & URO-D \\
\hline$-\mathrm{O}_{2}$ & Darkness & $21.9 \pm 2.2$ & $34.8 \pm 1.1$ & $37.9 \pm 1.7$ & $23.7 \pm 2.0$ \\
& UV light & $25.2 \pm 2.3$ & $38.1 \pm 2.3$ & $39.3 \pm 2.8$ & $24.4 \pm 2.4$ \\
$\mathrm{HO}_{2}$ & Darkness & $26.3 \pm 2.2$ & $43.7 \pm 1.5$ & $50.3 \pm 2.1$ & $25.8 \pm 3.1$ \\
& UV light & $50.1 \pm 2.0$ & $74.9 \pm 2.1$ & $75.2 \pm 2.8$ & $50.9 \pm 1.6$
\end{tabular}


Figure 4 - Effect of the presence of scavengers on the URO I-induced enzyme inactivation. ALAD, PBGase, PBG-D and URO-D were preincubated for $30 \mathrm{~min}$ at $30^{\circ} \mathrm{C}$ in the presence of histidine $(15 \mathrm{mM})$, sodium azide (15 $\mathrm{mM})$, catalase $(200 \mathrm{nM})$, reduced glutathione (15 mM), ethanol (15 $\mathrm{mM})$, glucose (11 mM ), dimethyl sulfoxide $(1.2 \mathrm{mM})$ or superoxide dismutase $(10 \mathrm{mM})$, and then exposed to $10 \mathrm{mM}(\mathrm{A}, \mathrm{B}, \mathrm{C})$ or $100 \mathrm{mM}$ (D) URO I for $2 \mathrm{~h}$ at $37^{\circ} \mathrm{C}$, under UV light.

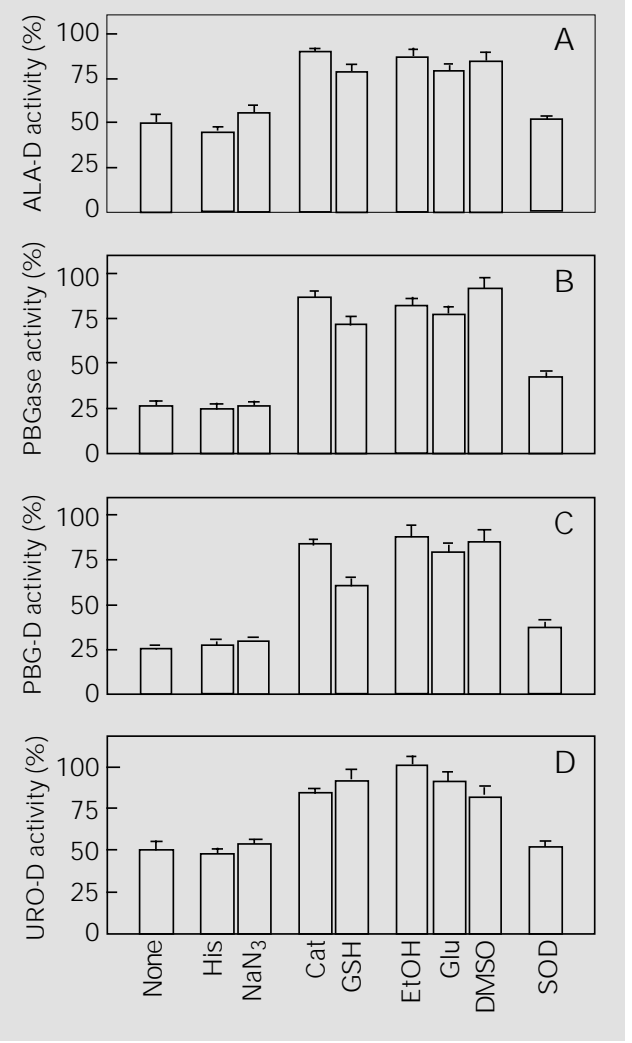

result of a direct inhibition due to conformational changes induced by the attachment of porphyrins on or near the active site of the enzymes. The photoinactivation would be produced by photooxidation of essential amino acids and the consequent inter- and/or intrapeptidic cross-linking of the protein, induced by the excited porphyrins (38-43).

\section{Mechanisms of photodynamic action}

To investigate the mechanism of photoinactivation induced by URO I, ALA-D, PBGase, PBG-D and URO-D were preincubated in the presence of specific scavengers for the different ROS and then exposed to the porphyrin and UV light, in an aerobic atmosphere (44). The presence of histidine or sodium azide did not protect the enzymes against the effect of URO I (Figure 4) (44); however, generation of singlet oxygen was detected during the treatment of PBG-D with URO I (Afonso SG, Enríquez de Salamanca
$\mathrm{R}$ and Batlle $\mathrm{A}$, unpublished results). In the presence of either catalase or GSH, enzyme photoinactivation was lower than in their absence, while ethanol, glucose and dimethyl sulfoxide prevented the URO I-induced photoinactivation (Figure 4) (44). These results indicate that a type I mechanism would be the main reaction through which the porphyrin exerts its photodynamic action, involving hydrogen peroxide and hydroxyl radicals, although singlet oxygen-mediated reactions (type II) could be produced simultaneously, contributing to enzyme photoinactivation yet to a much lesser extent (44).

Preincubation with superoxide dismutase did not protect any of the four enzymes from inactivation (Figure 4) (44) and no superoxide radical generation was detected during exposure of the enzymes to URO I and UV light (Afonso SG, Enríquez de Salamanca R and Batlle A, unpublished results). Bachowsky et al. (45) studied photooxidation reactions in ascorbate-containing erythrocyte membrane suspensions by monitoring formation of $\cdot \mathrm{OH}$ in the aqueous compartment, using URO I as sensitizer. They observed photoreduction of URO I to its radical anion ${ }^{-} \mathrm{URO}^{-}$by electron spin resonance and spin trapping when URO/ascorbate/ membrane mixtures were irradiated in anaerobiosis. Simultaneously, van Steveninck et al. (46) demonstrated that addition of increasing concentrations of URO I to a horseradish-peroxidase $/ \mathrm{H}_{2} \mathrm{O}_{2} / \mathrm{NADPH} / \mathrm{Fe}^{3+}$-EDTA/ deoxy-ribose mixture resulted in a gradual increased generation of $\cdot \mathrm{OH}$ even under anaerobic conditions, and omission of FeEDTA from the porphyrin-containing mixture blocked deoxyribose degradation. The authors explained these effects by assuming that the increased rate of NADPH oxidation producing increased concentrations of $\mathrm{NADP}^{+}$will generate URO I anion radical, which apparently replaces the superoxide radical, leading to hydrogen peroxide and to generation of ${ }^{\bullet} \mathrm{OH}$ in the iron-catalyzed reaction. They demonstrated the formation of 
- $\mathrm{URO}^{-}$by electron spin resonance spectra. Evidence for the photoreduction of hematoporphyrin or URO to their respective radical ions by reductants such as ascorbate, thiols, catechols, or reduced pyridine nucleotides has also been reported (47). These findings are in agreement with earlier electron spin resonance studies, where the formation of URO and other porphyrin radicals in the presence of electron donors was shown (48).

On these grounds and on the basis of our own results, a mechanism to explain the photodynamic action of URO I on ALA-D, PBGase, PBG-D and URO-D has been proposed (Figure 5) (44).

\section{Molecular alterations induced by porphyrins}

When proteins are irradiated with UV or visible light in the presence of a sensitizer, both photooxidation of sensitive amino acid residues such as cysteine, histidine, tyrosine, methionine and tryptophan and covalent cross-linking of peptide chains can be observed, leading to the formation of molecular aggregates $(6,11,12)$. It has been demonstrated that covalent cross-linking is not a primary photodynamic event, but a secondary reaction between photooxidation products of susceptible amino acid residues and other groups in the protein (6).

In the $\mathrm{pH}$ range between $7.0-8.5$, protein sulfhydryl groups are more sensitive to photooxidation, followed by histidine, tryptophan and tyrosine (3). However, the chemical nature of secondary cross-linking could not be attributed only to the formation of disulfide bridges, since dithiothreitol and dithioerythreitol reduction did not reduce the appearance of high molecular weight species in electrophoresis $(6,7,49)$.

Photooxidation of histidine, tyrosine or tryptophan in the presence of ${ }^{14} \mathrm{C}$-labeled non-photooxidizable amines yielded new ${ }^{14} \mathrm{C}$-labeled products, presumably generated by a reaction between the photooxidized

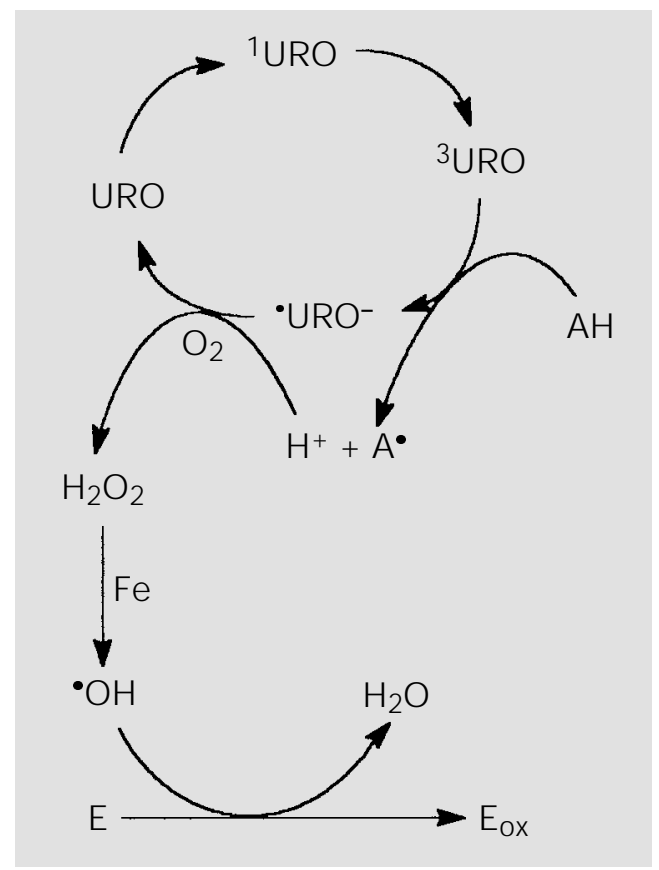

amino acid and the labeled amine. No reaction was observed between non-photooxidizable amino acids or amines on the one hand, and cysteine or methionine on the other. Instead, reactions did occur with tyrosine and tryptophan and were much more pronounced with histidine (6).

The crucial role of free amino groups was confirmed by the strong inhibition of crosslinking after succinylation of several protein amino groups before photooxidation $(3,6)$. During histidine photooxidation, nucleophilic addition of amino groups to the imidazole ring was observed; previous treatment with hydroxylamine, a strong nucleophilic reagent, protected against cross-linking (6). These results lead to the proposal of a molecular mechanism for cross-linking in which a histidine photooxidation product would react with amino groups on the protein via a nucleophilic addition (6).

A decrease of amino groups was observed during photooxidation of proteins which did not show interpeptide cross-linking on polyacrylamide gel electropherograms, like native myoglobin. The only obvious interpretation of these phenomena would be
Figure 5 - Mechanism of uroporphyrin action. URO: Uroporphyrin in the ground state; ${ }^{1}$ URO: singlet excited state uroporphyrin; ${ }^{3}$ URO: triplet excited state uroporphyrin; 'URO-: anionic radical uroporphyrin; $\mathrm{AH}$ : electron donor; E: native enzyme; $\mathrm{E}_{\mathrm{ox}}$ : photooxidized enzyme. 
the involvement of amino groups in the intramolecular cross-links. Because of this it is very likely that in proteins exhibiting intermolecular cross-linking, intramolecular cross-links will also occur (6).

The electrophoretic behavior of pure ALA-D, PBGase, PBG-D and URO-D treated in the presence of URO I was analyzed by SDS-PAGE. Enzymes showed some alterations in electrophoretic mobility, but the appearance of molecular aggregates was not revealed. Since variations in the content of free amino groups were observed, alterations in the electrophoretic pattern were attributed to intrapeptide cross-linking, which might change the molecule shape but does not modify the molecular weight. Mixtures of albumin and pure ALA-D or PBG-D were exposed to URO I or PROTO IX in the dark or under UV light. Electrophoresis of these reaction mixtures did not show protein bands other than those of the controls $(50,51)$.

Because within the living cell enzymes are included in a complex mixture of proteins and other biomolecules, the effect of porphyrins was analyzed on partially purified preparations of liver ALA-D and PBGD. Electrophoresis of the enzymes exposed for $2 \mathrm{~h}$ to URO I or PROTO IX showed the appearance of high molecular weight bands, suggesting that porphyrins might induce the formation of cross-links among different proteins, leading to the formation of heteropolymer structures. Electrophoresis of these preparations in the presence of SDS and $8 \mathrm{M}$ urea showed the same bands of high molecular weight. Instead, electrophoresis of samples treated with $\beta$-mercaptoethanol or dithiothreitol, before or after exposure of the enzymes to porphyrins, did not show the appearance of those bands (51). These results indicate that molecular aggregates may not be due to formation of disulfide bridges, but rather to covalent binding.

The percentage of sulfhydryl groups of liver ALA-D and PBG-D decreased upon treatment with URO I, but increased after exposure of the enzymes to PROTO IX. Even though sulfhydryl groups are not involved in the formation of molecular aggregates, URO I as well as PROTO IX affect these groups, although differently, and their action is not directly related to enzyme inactivation. The presence of sulfhydryl reagents during exposure of the enzymes to URO I or PROTO IX confirmed these findings and indicated that porphyrins may affect sulfhydryl groups at the active site of ALA-D and PBG-D (51).

Variations in the amount of free amino groups of liver ALA-D and PBG-D were observed upon exposure of the enzymes to URO I or PROTO IX. The effect of porphyrins was different for each enzyme, and again it was not directly related to enzyme inactivation. However, blockage of amino groups before treatment with URO I or PROTO IX partially protected the enzyme activities, and the electrophoretograms did not reveal the presence of high molecular weight bands. So, free amino groups may be involved in the porphyrin-photoinduced cross-linking, but may not be implicated in the effect of URO I and PROTO IX in the dark (51).

Nucleophilic addition of hydroxylamine to ALA-D and PBG-D before their exposure to porphyrins did not prevent the direct effect of URO I and PROTO IX on the proteins in the dark, but it did protect the enzymes from photoinactivation (51). Electrophoresis of these systems did not demonstrate the appearance of molecular aggregates (51), confirming the postulated mechanism of porphyrin-photoinduced cross-linking (6).

In the native (folded) state of the protein, hydrophobic residues are shielded from the aqueous environment, but denaturation and unfolding deprive the protein of this protection leading to its precipitation. In high salt solution, repulsion of hydrophobic groups by the solvent cage is maximized (52). Enzyme solubility of liver ALA-D and PBG-D in buffer containing $3 \mathrm{M} \mathrm{KCl}$ decreased with increasing time of treatment in the presence 
of URO I or PROTO IX, suggesting that porphyrins were interacting with the protein structure, exposing hydrophobic residues which are shielded in the core of the protein in its native configuration (53). These changes were observed when treatment was performed either under UV light or in the dark, although enzyme solubility was more affected in the former condition. This difference very probably reflects a different degree of exposure of hydrophobic residues during the unfolding of the proteins, and supports the theory of a double action of porphyrins in the dark and in the light.

It has been suggested that oxidized proteins are more sensitive to degradation by intracellular proteolytic enzymes (54). An increased susceptibility to proteolysis of a wide variety of proteins upon their exposure to hydroxyl radicals in vitro has been demonstrated $(53,55)$. Tryptic digestion of liver ALA-D and PBG-D exposed to URO I or PROTO IX resulted in an increase of protein degradation products. This effect was stronger when enzymes were exposed to porphyrins under UV light (53).

Alterations of the absorbance and fluorescence spectra of ALA-D and PBG-D were observed upon treatment of the enzymes with URO I or PROTO IX in the dark as well as under UV light (50).

Fluorescence emission by photosensitive amino acids was also modified after exposure of ALA-D and PBG-D to URO I or PROTO IX, and these changes were more pronounced when treatment was carried out under UV light. It was found that ALA-D was always more affected than PBG-D, and the action of URO I action was greater than that exerted by PROTO IX (53).

These findings suggest that porphyrins per se would induce alterations in the folding of the enzymes, leading to the exposure of some amino acid residues and the shielding of others. Photooxidation of sensitive amino acids upon irradiation of the enzymes in the presence of porphyrins would increase these changes, altering even more the fluorescence emission.

\section{Final considerations}

All porphyrias, with the exception of acute intermittent porphyria and ALA-D-deficient porphyria, include some form of cutaneous photosensitivity as a major manifestation among their associated clinical symptoms. All the photoactive porphyrins accumulated in the different porphyrias have the potential of initiating photooxidative chemical reactions by the same general mechanisms. However, patients with different forms of porphyria exhibit cutaneous lesions of varying morphology. The explanation for this phenomenon could lie in the wide differences in physicochemical properties of the various types of porphyrins accumulated in each porphyria as a result of the specific enzyme defect involved (27).

In vitro studies were performed to analyze the enzyme alterations induced by porphyrins and to elucidate the mechanism of their action. These studies indicated that tetrapyrroles exert a direct effect on the proteins. Furthermore, irradiation of the enzymes in the presence of porphyrins induces photodynamic reactions mainly mediated by hydrogen peroxide and hydroxyl radical generation, although singlet oxygen-mediated reactions could also occur. These photoinduced reactions contribute to the direct effect of porphyrins on the enzymes.

Porphyrins interact with the molecular structure of the enzymes, causing the folding-unfolding of the proteins. Such conformational changes result in the exposure of some groups normally shielded in the protein and shielding of others usually exposed in the molecule. These protein modifications lead to changes in properties such as solubility, proteolytic susceptibility, absorbance and fluorescence spectra and fluorescence emission of several of their amino acids. URO I and PROTO IX also affect the total sulfhy- 
dryl and free amino group content of the enzymes.

URO I and PROTO IX had different, and sometimes opposite effects on the proteins. Moreover, in some cases porphyrin-induced alterations were not the same for each enzyme studied. These findings indicate that the action of porphyrins would depend not only on its physicochemical properties but also on the specific site of the protein on which they act.

Several oxidative reactions mediated by ROS occur normally in the cells, which have a battery of defenses to prevent and repair the injury associated with these oxidative changes. It is only when the homeostatic mechanisms fail to keep pace with these reactions that detrimental effects become evident (56).

In all of the cutaneous porphyrias, alteration of the heme pathway leads to an excessive production and accumulation of porphyrins. Tetrapyrroles affect enzymes and proteins both isolated and in the cellular medium. Their action affects the functionality of the enzymes of the heme biosynthetic pathway, exacerbating the metabolic deficiencies in the case of porphyrias. Light energy absorption by circulating porphyrins results in ROS generation, and their abnormally high production exceeds the capacity of the cell defense mechanisms, leading to molecular, cellular and tissue damage, thus magnifying the porphyric picture.

From the above facts it emerges that if compounds are found or developed that can prevent or overcome the noxious effects due to the reactions and great imbalance occurring in the cells of porphyric patients, undoubtedly the general condition and welfare of the latter could be improved.

\section{Acknowledgments}

The collaboration of Dr. S. Chinarro and Dr. M.J. Morán (Spain) and Dr. A.M. Buzaleh, Dr. E.S. Vazquez and C. Polo (Argentina) is gratefully acknowledged.

\section{References}

1. MCDonagh AF \& Bissell DM (1998). Porphyria and porphyrinology - the past fifteen years. Seminars in Liver Disease, 18: 3-15.

2. Moore $M R, M c C o l l ~ K E L$, Rimington $C \&$ Goldberg A (1987). Disorders of Porphyrin Metabolism. Plenum Medical Book Co., New York \& London, 21-116.

3. van Steveninck J, Dubbelman TMAR \& Verweij H (1983). Photodynamic membrane damage. In: Kessel D \& Dougherty TV (Editors), Porphyrin Photosensitization. Plenum Press, New York, 227-240.

4. Batlle AM del C (1993). Porphyrins, porphyrias, cancer and photodynamic therapy. A model for carcinogenesis. J ournal of Photochemistry and Photobiology. B, Biology, 20: 5-22.

5. Sandberg S, Romslo I, Hovding G\& Bjorndal T (1982). Porphyrin-induced photodamage as related to the subcellular localization of the porphyrins. Acta Dermato-Venereologica, 100 (Suppl): 7580

6. Verweij H \& van SteveninckJ (1982). Mo- del studies on photodynamic cross-linking. Photochemistry and Photobiology, 35: 265-267.

7. Vincent SH, Holeman B, Cully BC \& Müller-Eberhard U (1986). Porphyrin-induced photodynamic cross-linking of hepatic heme-binding proteins. Life Sciences, 38: 365-372.

8. Sandberg S \& Brun A (1982). Light-induced protoporphyrin release from erythrocytes in erythropoietic protoporphyria. J ournal of Clinical Investigation, 70: 693698.

9. Girotti AW \& Deziel MR (1983). Photodynamic action of protoporphyrin on resealed erythrocyte membranes: mechanisms of release of trapped markers. Advances in Experimental Medicine and $\mathrm{Bi}$ ology, 60: 213-225.

10. Firey PA \& Rodgers MJ A (1988). Photochemical properties of erythrocyte ghosts containing porphyrin. Photochemistry and Photobiology, 47: 615-619.

11. De Goeij AFPM, Ververgaert PHJ T \& van Steveninck J (1975). Photodynamic ef- fects of protoporphyrin on the architecture of erythrocyte membranes in protoporphyria and in normal red blood cells. Clinica Chimica Acta, 62: 287-292.

12. Girotti AW (1976). Photodynamic action of protoporphyrin IX on human erythrocytes: cross-linking of membrane proteins. Biochemical and Biophysical Research Communications, 72: 1367-1374.

13. Brun A \& Sandberg S (1985). Photodynamic release of protoporphyrin from intact erythrocytes in erythropoietic protoporphyria: The effect of small repetitive light doses. Photochemistry and Photobiology, 41: 535-541.

14. Sandberg S \& Romslo I (1981). Porphyrininduced photodamage at the cellular and subcellular level as related to the solubility of the porphyrins. Clinica Chimica Acta, 28: 13-23.

15. J ori G, Reddi E, Cozzani I \& Tomio L (1986). Controlled targeting of different subcellular sites by porphyrins in tumourbearing mice. British J ournal of Cancer, 53: 615-621. 
16. Sandberg S, Glette J , Hopen G, Solberg C \& Romslo I (1981). Porphyrin-induced photodamage to isolated human neutrophils. Photochemistry and Photobiology, 34: 471-475.

17. Christensen T, Moan J , Brown J , Waksvik H \& Stigum H (1983). Studies on HPD: chemical composition and in vitro photosensitization. Advances in Experimental Medicine and Biology, 60: 151-164.

18. Lim HW, Gigli I \& Wasserman SI (1987). Differential effects of protoporphyrin and uroporphyrin on murine mast cells. J ournal of Investigative Dermatology, 88: 281286.

19. Konrad K, Hönigsmann H, Gschnait F \& Wolff K (1975). Mouse model for protoporphyria II. Cellular and subcellular events in the photosensitivity flare of the skin. J ournal of Investigative Dermatology, 65: 300-310.

20. Gomer CJ \& Razum NJ (1984). Acute skin response in albino mice following porphyrin sensitization under oxic and anoxic conditions. Photochemistry and Photobiology, 40: 435-439.

21. Dubertret L, Santus R, Bazin M \& de Sae Melo T (1982). Photochemistry in human epidermis. A quantitative approach. Photochemistry and Photobiology, 35: 103107.

22. Parrish J A, Rosen CF \& Gange RW (1985). Therapeutic uses of light. Annals of the New York Academy of Sciences, 454: 354-364.

23. Kohn K \& Kessel D (1979). On the mode of cytotoxic action of photoactivated porphyrins. Biochemical Pharmacology, 28: 2465-2470.

24. Sandberg S \& Romslo I (1980). Porphyrinsensitized photodynamic damage of isolated rat liver mitochondria. Biochimica et Biophysica Acta, 593: 187-195.

25. Moan J, Rognan SE, Evensen J F \& M alik Z (1987). Cell photosensitization by porphyrins. Photochemistry and Photobiology, 46 (Suppl): 385-395.

26. Lamola AA, Asher I, Müller-Eberhardt U \& Poh-Fitzpatrick MB (1981). Fluorometric study of the binding of protoporphyrin to haemopexin and albumin. Biochemical J ournal, 196: 693-698.

27. Poh-Fitzpatrick MB (1985). Porphyrin-sensitized cutaneous photosensitivity. Clinics in Dermatology, 3: 41-82.

28. Vazquez ES, Buzaleh AM, Navone NM, Polo CF, Schoua EA \& Batlle AM del C (1987). The effect of griseofulvin on the heme pathway. Studies on tissue explant cultures. Toxicology, 46: 73-82.

29. Rimington C, Lockwood WH \& Belcher
RV (1968). The excretion of porphyrin-peptide conjugates in variegate porphyria. Clinical Sciences, 35: 211-247.

30. Eales L, Day RS \& Blekkenhorst GH (1980). The clinical and biochemical features of variegate porphyria. International J ournal of Biochemistry, 12: 837-854.

31. Longas MO \& Poh-Fitzpatrick MB (1982). A tightly bound protein-porphyrin complex isolated from the plasma of a patient with variegate porphyria. Clinica Chimica Acta, 118: 219-228.

32. Varigos G, Schiltz J R \& Bickers DR (1982). Uroporphyrin I stimulation of collagen biosynthesis in human skin fibroblasts. J ournal of Clinical Investigation, 69: 129-135.

33. Ignarro LJ , Wood KS \& Wolin MS (1982). Activation of purified soluble guanylate cyclase by protoporphyrin. IX. Proceedings of the National Academy of Sciences, USA, 70: 2870-2873.

34. Khanum $F \&$ J ain $V$ (1989). Effects of hematoporphyrin derivative on the cellular energy metabolism in the absence and presence of light. Photochemistry and Photobiology, 50: 647-651.

35. Bodaness SR (1984). The nonphotosensitized potentiation by the photosensitizer hematoporphyrin of the horseradish peroxidase-catalyzed hydrogen peroxide-mediated oxidation of NADPH to NADP+ . Biochemical and Biophysical Research Communications, 118: 191-197.

36. van Steveninck J, Boegheim JPJ, Dubbelman TMAR \& van der Zee J (1988). The influence of porphyrins on iron-catalyzed generation of hydroxyl radicals. Biochemical J ournal, 250: 197-201.

37. Köningsberger J C, Rademakers LHPM, van Hattum J, Baart de la Faille $\mathrm{H}$, Wiegman LJ J M, Italiaander E, van Berge Henegouwen GP \& Marx J J M (1995). Exogenous protoporphyrin inhibits Hep G2 proliferation, increases the intracellular hydrogen peroxide concentration and causes ultrastructural alterations. J ournal of Hepatology, 22: 57-65.

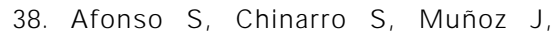
Salamanca RE \& Batlle A (1987). Lightdependent and light-independent inactivation of red cell porphobilinogenase and deaminase by type I and III porphyrins. Bollettino dell'Istituto Dermatologico San Gallicano, XIII: 35-40.

39. Afonso $S$, Chinarro $S$, Salamanca $R \&$ Batlle A (1991). Further evidence on the photodynamic and the novel non-photodynamic inactivation of uroporphyrinogen decarboxylase by uroporphyrin I. J ournal of Enzyme Inhibition, 5: 225-233.

40. Afonso SG, Chinarro S, Salamanca R \&
Batlle A (1994). $\delta$-aminolevulinic acid dehydratase inactivation by uroporphyrin I in light and darkness. International J ournal of Biochemistry, 26: 255-258.

41. Afonso SG, Salamanca R \& Batlle A (1996). Cytosolic and mitochondrial enzymes inactivation by uroporphyrin in light and darkness. J ournal of Enzyme Inhibition, 10: 141-146.

42. Afonso SG, Chinarro S, Muñoz J, Salamanca RE \& Batlle A (1990). Photodynamic and non-photodynamic action of several porphyrins on the activity of some heme-enzymes. J ournal of Enzyme Inhibition, 3: 303-310.

43. Afonso SG, Chinarro S, Enríquez de Salamanca R \& Batlle AM del C (1994). How the atmosphere and the presence of substrate affect the photo and non-photo inactivation of heme enzymes by uroporphyrin I. International J ournal of Biochemistry, 26: 259-262.

44. Afonso SG, Polo CF, Enríquez de Salamanca R \& Batlle A (1996). Mechanistic studies on URO I-induced enzyme photoinactivation. International J ournal of Biochemistry and Cellular Biology, 38: 415420.

45. Bachowsky GJ , Morehouse KM \& Girotti AW (1988). Porphyrin-sensitized photoreactions in the presence of ascorbate. Oxidation of cell membrane lipids and hydroxyl radical traps. Photochemistry and Photobiology, 47: 635-645.

46. van Steveninck J, Boegheim J PJ, Dubbelman TMAR \& van der ZeeJ (1988). The influence of porphyrins on ironcatalized generation of hydroxyl radicals. Biochemical J ournal, 250: 197-201.

47. Buettner GR \& Hall RD (1987). Superoxide, hydrogen peroxide, and singlet oxygen in hematoporphyrin derivative, cysteine, NADPH and light systems. Biochimica et Biophysica Acta, 923: 501-507.

48. Mauzerall D \& Fehrer G (1964). A study of the photoinduced porphyrin free radical by electron spin resonance. Biochimica et Biophysica Acta, 79: 430-432.

49. Girotti AW (1979). Protoporphyrin-sensitized photodamage in isolated membranes of human erythrocytes. Biochemistry, 18: 4403-4411.

50. Afonso SG, Enríquez de Salamanca R \& Batlle A (1997). Porphyrin induced protein structural alterations of heme enzymes. International J ournal of Biochemistry and Cellular Biology, 29: 1113-1121.

51. Afonso SG, Enríquez de Salamanca R \& Batlle A (1998). Porphyrin induced protein structural alterations of heme enzymes. II. Protection of ALA-D and PBG-D from 
the photodynamic and non-photodynamic effects of URO and PROTO. International $J$ ournal of Biochemistry and Cellular Biology, 30: 535-543.

52. Davies KJ (1987). Protein damage and degradation by oxygen radicals. I. General aspects. J ournal of Biological Chemistry, 262: 9895-9901.

53. Afonso SG, Enríquez de Salamanca R \&
Batlle AM del C (1997). Folding and unfolding of $\delta$-aminolevulinic acid dehydratase and porphobilinogen deaminase induced by URO and PROTO porphyrin. International J ournal of Biochemistry and Cellular Biology, 29: 493-503.

54. Dean RT (1987). A mechanism for accelerated degradation of intracellular proteins after limited damage by free radicals.
FEBS Letters, 220: 278-282.

55. Davies KJ , Lin SW \& Pacifici RE (1987) Protein damage and degradation by oxygen radicals. IV. Modification of denatured protein. J ournal of Biological Chemistry, 262: 9914-9920.

56. Kehrer J P (1993). Free radical as mediators of tissue injury and disease. Critical Reviews in Toxicology, 23: 21-48. 